Relations industrielles

Industrial Relations

\title{
Teachers and Unions, by Michael H. Moskow, University of Pennsylvania, Wharton School of Finance and Commerce, Industrial Research Unit, 1966, 288 pages.
}

\section{Gilles Richard}

Volume 22, numéro 2, 1967

URI : https://id.erudit.org/iderudit/027799ar

DOI : https://doi.org/10.7202/027799ar

Aller au sommaire du numéro

Éditeur(s)

Département des relations industrielles de l'Université Laval

ISSN

0034-379X (imprimé)

1703-8138 (numérique)

Découvrir la revue

Citer ce compte rendu

Richard, G. (1967). Compte rendu de [Teachers and Unions, by Michael H.

Moskow, University of Pennsylvania, Wharton School of Finance and

Commerce, Industrial Research Unit, 1966, 288 pages.] Relations industrielles /

Industrial Relations, 22(2), 306-306. https://doi.org/10.7202/027799ar

Tous droits réservés @ Département des relations industrielles de l'Université Laval, 1967
Ce document est protégé par la loi sur le droit d'auteur. L'utilisation des services d’Érudit (y compris la reproduction) est assujettie à sa politique d'utilisation que vous pouvez consulter en ligne.

https://apropos.erudit.org/fr/usagers/politique-dutilisation/ 
rendez-vous, les visiteurs, la classification des dossiers. Sans connaissances bien spécifiques dans le domaine, on peut retrouver une foule de conseils pratiques, utiles à l'étudiant et à celui qui, dans la pratique doit faire face à tel ou tel problème.

La deuxième partie de ce premier volume traite de la délśgation de pouvoir. Qu'est-ce que l'autorité ? Quelles sont les responsabilités respectives? Voilà des questions que I'on tente de résoudre. Les relations supérieur-subordonnés sont abordées d'une façon très protique, de même que les divers comportements possibles de part et d'autre.

Le volume deuxième traite du planning et de la prise de décision. L'auteur insiste sur la première partie. II réussit à montrer ce qu'est le planning, en quoi consiste le processus; il énumère certains écueils à éviter, de même que les responsabilités propres des personnes chargées du planning. Mais toujours il y a cet aspect du quotidien qui rend le volume beaucoup plus intéressant, et la lecture plus utile.

Le second développement de ce volume répond à des questions du genre: Comment prendre une décision? Comment décider personnellement et collectivement? Quelles sont les décisions efficaces?

La dernière section de Principes de direction des entreprises est réservée au contrôle de direction et au travail de direction lui-même. II examine avec soin les différents types de contrôle, la vérification des résultats, les inspections, la surveillance, l'amélioration de la production, sans oublier celui qui doit exercer le contrôle.

Une dernière partie vient compléter cette source de renseignements en élaborant quelque peu les exigences du travail de direction. C'est un genre de tableau sommaire, descriptif, des exigences du travail de direction de I'entreprise.

Bref, pour celui qui travaille seul, Principes de direction des entreprises est un ouvrage à consulter. Cet enseignement programmé peut rendre de précieux services à celui, qui est dans l'entreprise et à l'étudiant qui veut préciser quelques connaissances dans le domaine de direction des entreprises.

\section{Michel BERGERON}

Teachers and Unions, by Michael H. Moskow, University of Pennsylvania, Wharton School of Finance and Commerce, Industrial Research Unit, 1966, 288 pages.
Le présent ourrage de M. Moskow, nous offre une étude assez intéressante du phénomène syndical chez les enseignants du secteur public aux Etats-Unis. Cette étude a l'avantage de nous présenter la situation sous un double aspect: d'abord, sous son ospect statique, à savoir, la description détaillée du système d'enseignement américain; puis, sous son aspect dynamique, en essayant de dégager les pressions introduites dans le système crec le développement du syndicalisme ou sein de la profession et de poser les différents problèmes qui se rencontrent

Les premiers chapitres de l'ouvrage constituent la partie plus descriptive dans laquelle l'cuteur précise le mode de financement du système, les structures administratives et, de plus, le contenu de la législation qui régit le système.

La deuxième partie met en évidence l'élément dynamique de la situation, introduit au cceur du système avec le développement du syndicolisme. II tente de préciser les problèmes auxquels il doit faire face.

Les problèmes auxquels se heurtent les syndicats sont situés à deux niveaux. Le premier problème se situe au niveau des objectifs, à savoir, le choix entre la négociation directe comme le préconise la AFT (American Federation of Teachers) ou la revalorisation de la profession, en mettant l'accent sur le statut professionnel, préconisée par la NEA (National Educational Association). Les autres problèmes se situent surtout au niveau structurel, comme la composition du marché du travail ou le cadre juridique et législatif, qui rend difficile la reconnaissance syndicale, la définiton de I'unité de négocation et, l'utilisation du pouvcir de négociation

Cette étude, jetant un peu de lumière sur le développement du syndicalisme au sein du système d'enseignement américain, nous arrive à un moment où plusieurs problèmes se posent dans notre secteur de l'éducation. Cet ouvrage ne manquera sûrement pas d'intéresser notre public déjà en éveil

\section{Gilles RICHARD}

The Motivation to Work, Bernard P. Indik, Institute of Management and Labor Relations, Rutgers - The State University, New Brunswick, New Jersey, 73 pages.

Ce raport doit être examiné en corrélation avec celui qui porte sur: "The Se- 